\title{
Investigation of Relevance between Landslide and Stand Properties using Open Source Web Map (OpenLayers): Case Study in Trabzon Region*
}

\author{
Selçuk Gümüş (D), Taha Yasin Hatay** (iD), Saliha Ünver Okan (D) \\ Karadeniz Technical University, Faculty of Forestry, 61080 Trabzon, Turkey
}

\begin{abstract}
In recent years, the developments in computer technology are as effective in forestry as in many sectors. Open source web map based Geographic Information Systems (GIS) offer a significant advantage in investigating forest structure. When using in open source web maps, the relationships between the data of different features can be evaluated effectively and accurately. In this study, the relationship between online landslide data and online stand data was investigated by coding a web interface with OpenLayers which is one of the common open source web maps. OpenLayers based landslide areas and ArcGIS Web Services based stand areas have been evaluated in the solution process. The parameters of the landslide stands have been evaluated in a case study conducted in Trabzon Regional Directorate of Forestry. Landslide data were obtained from the General Directorate of Mineral Research and Exploration, while stands data were obtained from General Directorate of Forestry. The results indicated that most of the active landslide areas consisted of pure stands (26.71\%), mixed stands (20.50\%), and agricultural areas (38.51\%). It was found that $14.29 \%$ of active landslide areas consisted of degraded forest and open areas while $38.51 \%$ consisted of agricultural lands. The results also indicated that stands with sparse crown closure covered $32.30 \%$ of the active landslide areas, while moderate and dense crown closures covered $12.42 \%$ and $2.48 \%$, respectively. It was revealed that percentages of landslide areas were high in stands with low crown closure due to effects of heavy rain on the soil. It was also found that mostly tree species with narrow canopy and shallow root formation are subject to landslide incidents. This study suggested that OSWMs can be effectively used to investigate landslide activities in forest areas. It is anticipated that sharing open source data through online databases will provide great opportunity for practitioners and researchers in the field of forestry.
\end{abstract}

Keywords: Open source web map, OpenLayers, GIS, Landslide, Forestry

\section{Introduction}

Improvements in spatial inquiry technologies have led to revolutionary advances in access to reliable information sources and the generation of large data sets. Open source software, web mapping applications, data pools, computer based modeling and access to geographic information have been developing positively over the years. This provides a bridge between the access and use of global information within the planning and decision-making processes (Johansson et al., 2019).

In recent years, many web-based decision support services have been used for environmental purposes such as watershed management (Zhang et al., 2015), integrated pest management (Damos, 2015), pest infestation (Lajis et al., 2016) and ecosystem services (Tayyebi et al., 2016) by using GIS over the Web. By using web-based GIS projects, software and data storage will increase the adoption of geographic technologies in countries with limited economic resources (Cope et al., 2017). This Web mapping-based decision support services can be effectively applied in the field of forestry. Technological developments in the field of forestry are undergoing a process of integration with new technologies under the influence of GIS. Forestry activities that carry out different functions remain in communication with each other during this integration process. For example; studies that ensure the continuity and sustainability of forests such as silviculture, forest protection, forest transportation, habitat classification, forest management plans, erosion, and soil conservation studies are clarified with their internal regulations. Spatial arrangements are carried out in an economic, sociocultural and ecological manner in accordance with the basic characteristics of the ecosystem. GIS enables all kinds of forest maps to be prepared, stored digitally, updating forest inventory, carrying out activities and carrying out computer operations such as modern information systems.

Some project groups have recently emerged focusing on the development of free and open source GIS

\footnotetext{
* This work has been partially presented in PEFOSS 2018 Symposium

***Corresponding author: Tel: +90 4623772818 E-mail: tyhatay@ktu.edu.tr 
software. These groups led to a different market environment. In particular, services such as OpenLayers, Quantum GIS Project, ArcGIS Server, GEBCO Web Map Services, and GeoServer have increased the functionality of the software. The fact that the free software system can be improved at any time and always has a movement within itself which has increased the attractiveness of GIS users positively (Steiniger and Hunter, 2012).

Open source is free, reusable and distributable data and information that is free to everyone, irresponsible for any copyright, patent or other control mechanisms. Open source maps are visual mapping from GIS data with reusable information without inclusion in any control mechanism. It is known that open-source geospatial studies are carried out by developers and users with the work of communities such as FOSS4G, FreeGIS, and OSGeo foundation (Ramsey, 2006; Bruce, 2007; Sherman, 2008).

In a study conducted by Torre (2005), many types of web-based open source geographic software were categorized as; desktop viewer, web client, file converter, server based, interlayer software, and database management. Web services have been used by companies and government agencies for collecting information clutter, reusability, flexibility, and platform independence (Shen et al., 2007). This situation has encouraged people to organize common specifications of GIS to be used as open source tools. The Open Source GIS Consortium (OGC) 318 is an international industrial consortium that develops publicly available specifications through joint decisions made in collaboration with companies, governments and universities (Turan, 2006). Web based GIS systems used on an Internet-based basis must comply with the specifications of this consortium.

Open source Web Maps are the integration of GIS and internet technologies. GIS provides solutions to prevent the use of information, which is one of the most important problems of its users. Open source web maps are seen as a tool for accessing, analyzing and transmitting GIS data. World Wide Web, FTP (file transfer protocol) and HTTP programs make it easy to access and transfer data files through open source web maps (Karnatak, 2016). Online GIS users are provided with easy access to receive GIS data from different data sources in a distributed environment. GIS users can use or download any data with the web browser application.

With the development of technology, interest in developing open source web map applications has increased. SDKs or APIs, which are software developer libraries, vary in terms of viewing geographic data over the web. This can be related to the "open source" development of web map applications. In these developer libraries, there is a large use and development intensity in the JavaScript language, which is used as a client web programming language (Neumann, 2012).
Open source web maps have a dynamic structure. For example, when any client or database administrator updates the data or information on the server, all GIS users who are in the client state on the internet can use the data at the same time. Open source web maps have online databases systems with a specific file system. The map server incorporated with this database can see, monitor, and intercept GIS data with specific applications (Figure 1). This is the basis for an interactive map which can be updated at any time and compatible with Web map services (WMS). WMS introduces HTTP interface that get geo-registered web images from geospatial databases (Scharl and Tochtermann, 2009).

The use of online web map has been increasing in many parts of the world, as well as In Turkey. ARCGIS Web Server based online mapping system generated by the General Directorate of Forestry provides instant access to information such as stand maps, regional management boundaries. By using the OpenLayersbased online map system developed by General Directorate of Mineral Research and Exploration, soil maps of Turkey can be displayed and the regions subject to erosion and landslide can be detected. On the other hand, Duman et al. (2005) argued that General Directorate of Mineral Research and Exploration's data still need inventory to assess the hazards of landslides and reliable inventory data has a primary importance and impact, in particular for field evaluation processes and land use planning procedure. However, current data, which were adopted in previous researches such as Duman et al. (2005) and Turner et al. (2010), are too narrow ranged (less than $400000 \mathrm{ha}$ ) for open source online mapping systems. The main advantage of online mapping systems is that they provide great convenience in larger databases. For this reason, the data of General Directorate of Mineral Research and Exploration can be adapted for online mapping systems.

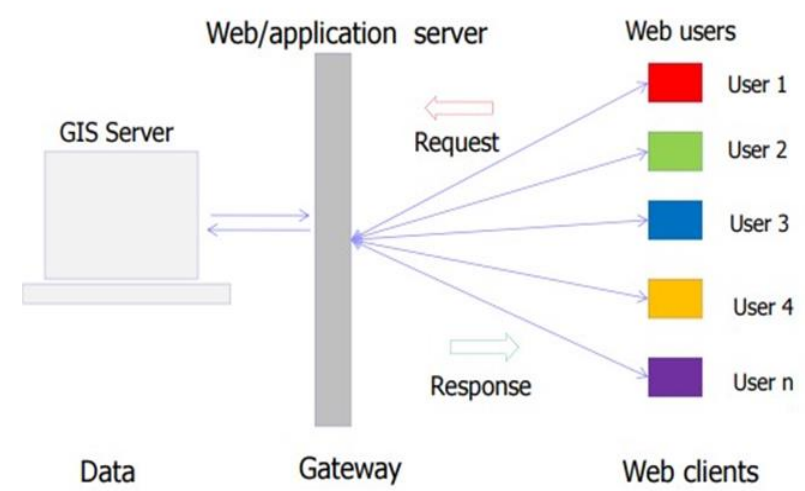

Figure 1. The principle of Web Map systems (Karnatak, 2016)

Interactions of forests with landslide activities have a very complex system (Mulder et al., 1987) since many factors play a role in the formation of landslides. Landslide formation is based on geological periods, but earth movements may also depend on climatic conditions as well as external events such as erosion and weather. 
The positive effects of forests on landslides are generally evaluated in terms of hydrological and mechanical aspects. Hydrological effects is evaluated by the prevention of soil moisture and precipitation water reaching the soil. Mechanical effects are due to the soil retention properties on soil stability. The mechanical effects of forests on landslides are especially positive if the soil is shallow.

The negative effects of the forests are due to overload thrusts on the slope according to the location of the trees. In addition, forests are exposed to wind load which causes downward movement of the mass on the slope. Based on the above information, the risk of landslide should be taken into account when evaluating the functions of forests. This risk is to be integrated not only in terms of forest management plans but also in all watershed management. Within this context, landslides have been mapped based on analysis of aerial photographs and field data in landslide inventory projects in Turkey. In the projects, there are historical landslide inventory maps which include all existing landslides that are morphologically identifiable. In mapping studies related to landslides, there are certain limitations such as type of moving material, size and depth of moving mass, type and speed of movement, size of study area, and map scale. The landslide database of the General Directorate of Mineral Research and Exploration was structured into 1: 25.000 scaled topographic maps with detailed aerial photography and field studies. (Can et al., 2013; Eker and Aydin, 2014). The aim of the study is to determine the relationship between online landslide data and online stand data by coding a web interface with OpenLayers which uses PHP and JavaScript SDK.

\section{Material and Methods \\ 2.1. Study Site and Data}

The study was carried out in Trabzon Regional Directorates of Forestry (RDF) (Figure 2). The total area of the study area is 468500 ha and approximately $59.6 \%$ of this area is covered with forests. Considering that $27.6 \%$ of Turkey is covered with forests, this area is seen to have higher rate of forest than the national average rate of forest (GDF, 2017).

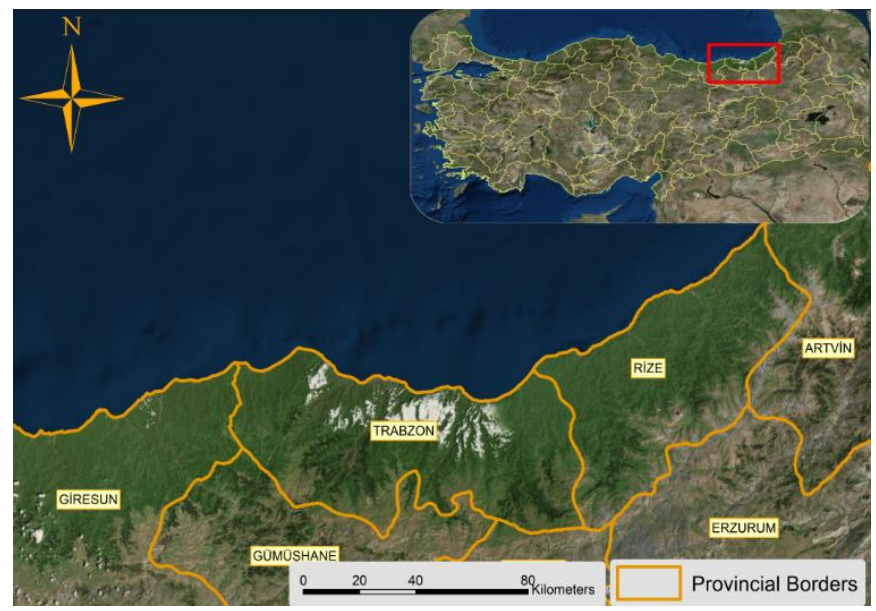

Figure 2. Overview of the study area

\subsection{Methods}

In the study, OpenLayers based online mapping system of General Directorate of Mineral Research and Exploration was used to identify landslide areas in the study area. The stand maps were obtained from ArcGIS Web Server based online mapping system of General Directorate of Forestry (Figure 3).

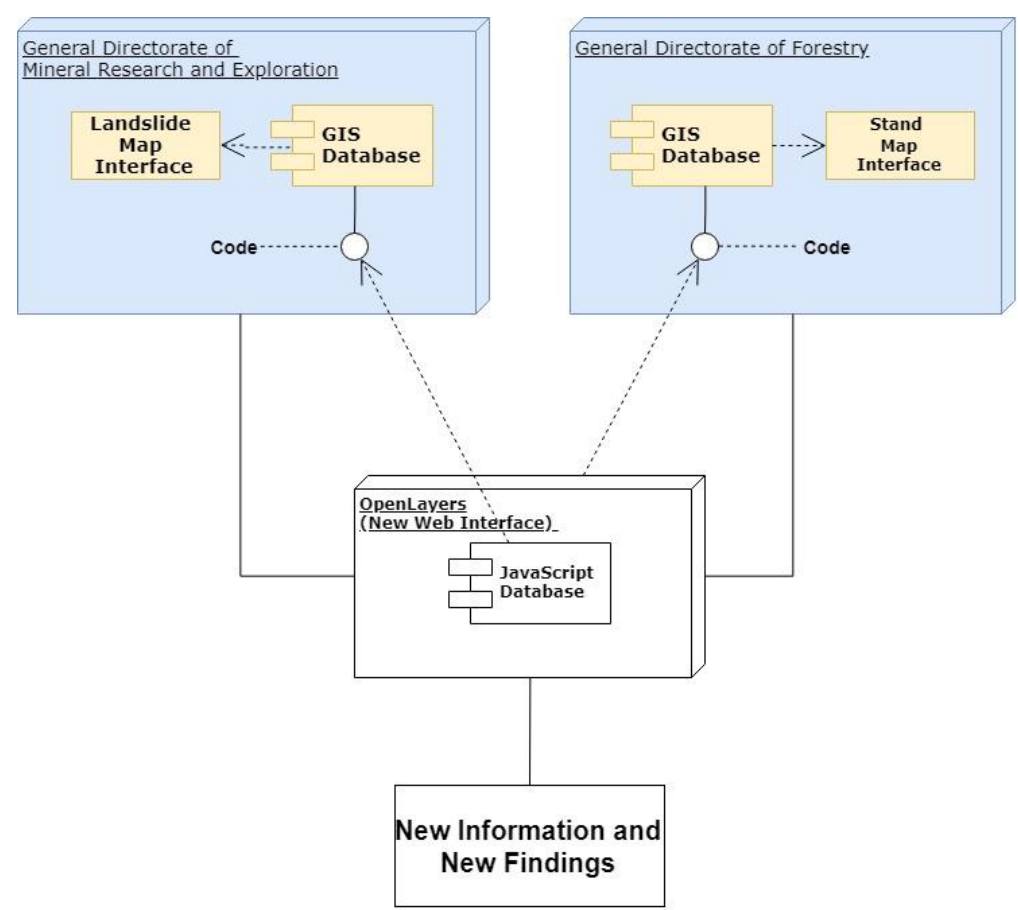

Figure 3. Flowchart showing the operations performed 
OpenLayers4, which is one of the open source web map systems, has been selected in order to overlap the specified data and to examine in detail. The reason for choosing OpenLayers is that the system is completely free, and the JavaScript language and OpenLayers library are easy and flexible to use. In addition, one of the web mapping systems to be examined is based on OpenLayers. In order to produce the data to be analyzed, a SQL-based database was generated. The web interface has been developed by using Javascript and Php languages so that information can be displayed and accessed online. (Figure 4). The connection between the Web interface and the SQL database has been established and the landslide areas and the stand maps data were recorded in the database system with the connection protocol. The database system was encrypted for information security of institutions and the authoring and modification rights of databases were revoked. Then, the database was transferred to the web interface and the online map model was produced (Figure 4). In addition to this, online maps such as Google Roadmap and Google Map were included as sub-layers. WGS-84 system was selected as projection and datum system. A visibility setting between layers has been added to make it easy to view on the web interface. In order to show the coordinate value while the cursor is moving on the map, a coordinate pointer was added.

The areas of landslide and the stand maps in the study area were presented online on the same map. By generating the database system, a new online map that can be queried was produced and the relations between the stand parameters and the landslide characteristics have been revealed.

\section{Results and Discussion}

In the study, active landslide areas, previous landslide areas, and active soil slide have been examined. The properties of landslide areas are given in Table 1. The total number of landslides was found to be as 355 in which the number of active landslide were 161. It was also found that the previous landslides were 194, while 24 areas were exposed to active soil slide. The results indicated that the total perimeter and area of the landslide was $730.54 \mathrm{~km}$ and $11879.03 \mathrm{ha}$, respectively.

Table 1. General information of landslide areas

\begin{tabular}{lccc}
\hline & $\begin{array}{c}\text { Active } \\
\text { Landslide }\end{array}$ & $\begin{array}{c}\text { Previous } \\
\text { Landslide }\end{array}$ & $\begin{array}{c}\text { Active Soil slide } \\
\text { (can be mapped) }\end{array}$ \\
\hline Number & 161 & 194 & 24 \\
Perimeter (km) & 370.10 & 329.71 & 30.73 \\
Area (ha) & 5927.24 & 5724.16 & 227.63 \\
\hline
\end{tabular}

The relationships between the stand types and the landslides in terms of distribution areas were indicated in Table 2. According to results, landslide areas and soil slide areas were mostly concentrated in agricultural lands. It is considered that landslides were more common in agricultural areas due to the lack of tree species with soil-retaining root structure. It was found that the second highest percentage of the landslides was in pure forest stands for both active and previous landslides. The percentage of landslides in mixed forest stands $(20.50 \%)$ were lower than that of pure forest stands. Mixed stands consisting of different tree species have different root structures may be more advantageous in terms of soil retention than pure forest stands.

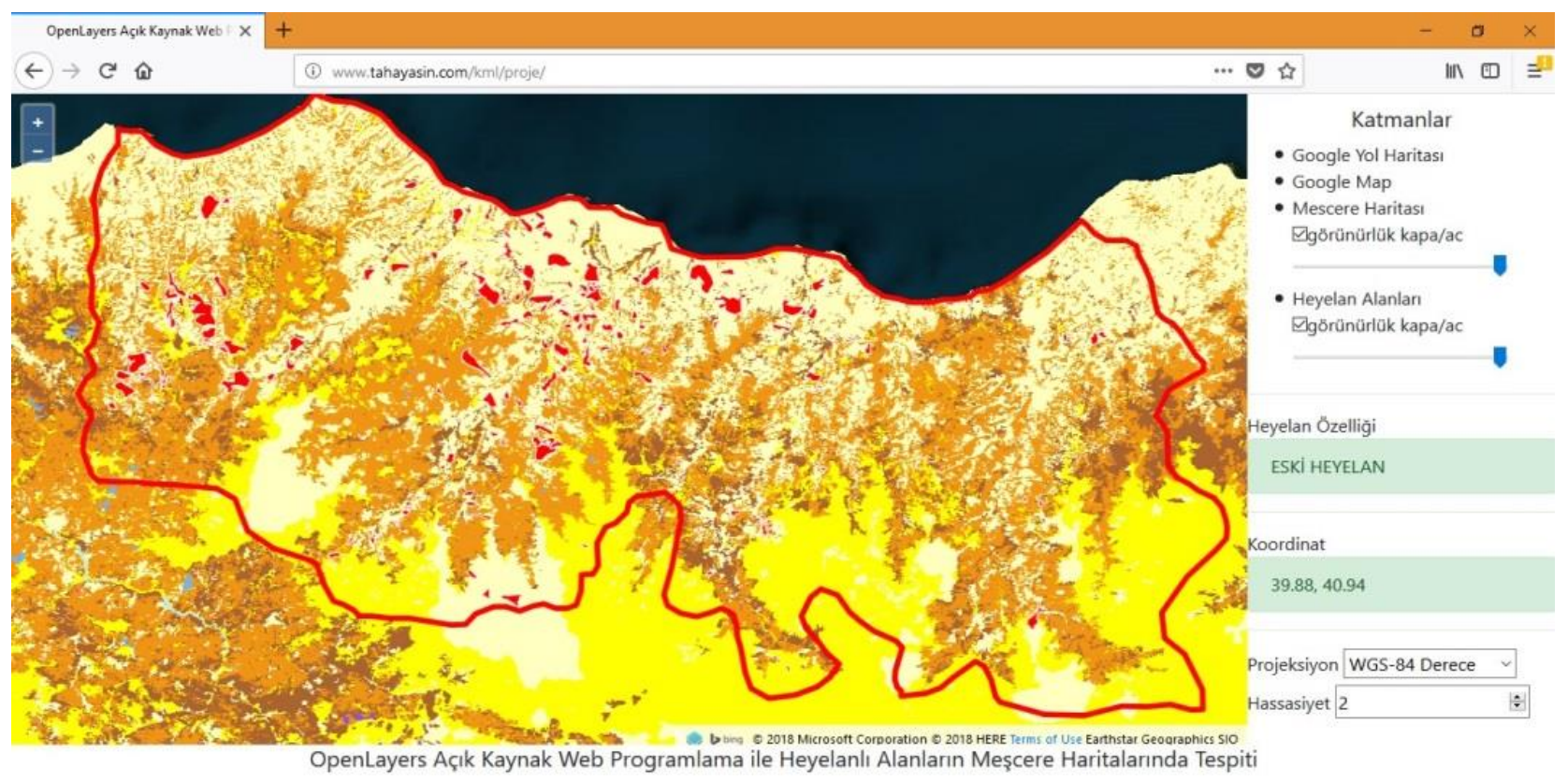

Figure 4. Coded stand map and landslide web interface 
Table 2. The relationship between the stand types and landslides

\begin{tabular}{lccc}
\hline Stand Types & $\begin{array}{c}\text { Active } \\
\text { Landslide } \\
(\%)\end{array}$ & $\begin{array}{c}\text { Previous } \\
\text { Landslide } \\
(\%)\end{array}$ & $\begin{array}{c}\text { Active Soil slide } \\
\text { (can be mapped) } \\
(\%)\end{array}$ \\
\hline Pure Forest & 26.71 & 24.23 & 12.50 \\
Mixed Forest & 20.50 & 18.56 & 8.33 \\
Degraded Forest & 11.18 & 7.73 & 29.17 \\
Open Areas & 3.11 & 7.73 & 12.50 \\
Agriculture & 38.51 & 41.75 & 37.50 \\
\hline
\end{tabular}

In degraded forest, percentage of active soil slides (29.17\%) were more than both the active landslides and previous landslides. In pure stands, the percentage of the previous landslide areas (24.23\%) was close to the active landslide areas. Similar to previous studies, it was found that forest cover increases sensitivity to landslides and shows positive effects in most cases (Rice, 1977). The landslide formation is generally low in basins with undisturbed forests (Forbes and Broadhead, 2011).

The relationships between stand development stages and landslides with respect to distribution areas were indicated in Table 3. It was found that percentages of landslide areas were generally high in stage of "bc" with average DBH of 20.0-35.9 cm. In this development stage, the tree diameters are still relatively small and the soil retention properties and water retention properties are not fully developed in young stages. On the other hand, the weight of the trees can affect the bearing capacity as an additional load on the slope of the soil in the landslide direction (Chok, 2008). Thus, mature stands can be more susceptible to landslides.

Table 3. The relationship between stand stages and landslides

\begin{tabular}{lccc}
\hline $\begin{array}{l}\text { Development } \\
\text { Stages } \\
(\text { DBH*) }\end{array}$ & $\begin{array}{c}\text { Active } \\
\text { Landslide } \\
(\%)\end{array}$ & $\begin{array}{c}\text { Previous } \\
\text { Landslide } \\
(\%)\end{array}$ & $\begin{array}{c}\text { Active Soil slide } \\
\text { (can be mapped) } \\
(\%)\end{array}$ \\
\hline a (<7.9) & 0.62 & 0.52 & 0.00 \\
ab (1.30-7.9) & 2.48 & 1.55 & 4.17 \\
b (20.0-35.9) & 1.86 & 3.09 & 4.17 \\
bc (20.0-35.9) & 24.22 & 24.74 & 4.17 \\
c (36.0-51.9) & 2.48 & 2.58 & 0.00 \\
cd (36.0-51.9) & 13.66 & 9.28 & 4.17 \\
d (>52) & 1.86 & 1.03 & 4.17 \\
\hline
\end{tabular}

*Diameters of breast height $(\mathrm{cm})$ at $1.3 \mathrm{~m}$ from the ground

In Table 4, the relationship between the crown closures and landslide distribution was presented. It was found that the areas with active landslides were in the stands with sparse and moderate crown closures. Landslides can be seen in stands with low crown closure especially in regions with intense and long precipitation period such as the Eastern Black Sea Region (Kumar and
Table 4. The relationship between the crown closures and landslides

\begin{tabular}{lccc}
\hline $\begin{array}{l}\text { Crown } \\
\text { Closures }\end{array}$ & $\begin{array}{c}\text { Active } \\
\text { Landslide } \\
(\%)\end{array}$ & $\begin{array}{c}\text { Previous } \\
\text { Landslide } \\
(\%)\end{array}$ & $\begin{array}{c}\text { Active Soil slide } \\
\text { (can be mapped) } \\
(\%)\end{array}$ \\
\hline Sparse $(11-40 \%)$ & 32.30 & 22.16 & 8.33 \\
Moderate $(41-70 \%)$ & 12.42 & 15.46 & 8.33 \\
Dense $(>0.70 \%)$ & 2.48 & 5.15 & 4.17 \\
\hline
\end{tabular}

Bhagavanulu, 2008). On the contrary, the percentages of landslide areas decreased as the crown closure increased since plants retain rainwater in the crowns and prevent water from reaching the soil. This process allows the retained water to evaporate on the crown, which reduces the infiltration of precipitation waters in soils. Therefore, the effect of water on the soil will be less in the stands where the closure is high (Chok, 2008).

Table 5 showed the relationship between tree species and landslides in the study area. It was seen that Alnus was the tree species that has the most landslides among the species. Alnus is one of the most common tree species in the region; therefore, it can be considered that active landslide is mostly located in Alnus stands. Although natural stand formation in the Eastern Black Sea Region is decreasing the landslide effect, it does not show sufficient preventive effect. Picea, which is endemic tree species in the region, is one of the species with high active landslide rate. Picea has narrow canopy, as well as shallow root formation. It was reported that landslides mostly occur on stands with shallow roots while soil movements reduce in deep rooted trees (Forbes and Broadhead, 2011).

Table 5. The relationship between tree species and landslides

\begin{tabular}{lccc}
\hline $\begin{array}{l}\text { Tree } \\
\text { Specie }\end{array}$ & $\begin{array}{c}\text { Active } \\
\text { Landslide } \\
(\%)\end{array}$ & $\begin{array}{c}\text { Previous } \\
\text { Landslide } \\
(\%)\end{array}$ & $\begin{array}{c}\text { Active Soil slide } \\
\text { (can be mapped) } \\
(\%)\end{array}$ \\
\hline Pinus Sylv. & 0.62 & 0.00 & 0.00 \\
Abies & 0.00 & 0.00 & 0.00 \\
Carpinus & 3.73 & 7.22 & 0.00 \\
Fagus & 4.35 & 2.58 & 8.33 \\
Castanea & 4.35 & 7.22 & 0.00 \\
Alnus & 19.88 & 11.86 & 8.33 \\
Picea & 14.29 & 13.40 & 4.17 \\
Quercus & 0.00 & 0.52 & 0.00 \\
\hline
\end{tabular}

\section{Conclusions}

This study investigated the relationship between some of the stand parameters which can be accessed online with ArcGIS Server system of the General Directorate of Forestry and the landslide data which are available online with OpenLayers Online Web Map system of General Directorate of Mineral Research and 
Exploration. The GIS analysis was performed based on OpenLayers based internet interface, which is coded with PHP and JavaScript programming languages and database system suitable for this interface. As a result, total number of landslides were 355 where 161 of them were previous landslide areas while 24 of them were active soil slide. The results indicated that the most landslides were seen in the pure forest stands, in the developmental stage of bc $(20.0-35.9 \mathrm{~cm})$ and in the stands with a sparse crown closure $(0.11-0.40 \%)$. In addition, the active landslides mostly occurred in stands with Alnus and Picea stands. Open source web maps are effective platforms that can be used to identify the forest and external factors that affect the forest resources. Online mapping systems can be used more efficiently if all relevant stakeholders in the field of forestry can involve the online information system in open source format. Open source web information systems should be made available to public institutions and organizations as well as companies engaged in forestry activities in the private sector. Thus, the databases can be used more efficiently and relations among forestry activities can be examined and recorded using the information network. People involved in forestry activities should be trained about the use of open source Web Map systems, and as in this study, the interest of people should be drawn to benefits of using open source platforms.

\section{References}

Bruce, B., 2007. A Survey of Open Source Geospatial Software, MUUG Meeting.

Can T., Duman T. Y., Olgun S., Corekcioglu S., Karakaya Gulmez F., Elmaci H., Hamzacebi S., Emre Ö., 2013. Landslide Database of Turkey, Union Of Chambers Of Turkish Engineers And Architects Congress of Geographical Information Systems, 1113 November, Ankara.

Chok, Y.H., 2008. Modelling the effects of soil variability and vegetation on the stability of natural slopes. Doctor of Philosophy, the University of Adelaide, School of Civil, Environmental and Mining Engineering.

Cope, M., Mikhailova, E., Post, C., Schlautman, M., McMillan, P., 2017. Developing an integrated cloudbased spatial-temporal system for monitoring phenology. Ecol Inform 39:123-129.

Damos, P., 2015. Modular structure of web-based decision support systems for integrated pest management. A review. Agron Sustain Dev 35(4):1347-1372.

Duman, T.Y., Çan, T., Emre, Ö., Keçer, M., Doğan, A., Ates, S., Durmaz, S., 2005. Landslide inventory of northwestern Anatolia, Turkey. Engineering Geology 77(2005):99-114.

Eker R., Aydin A., 2014. The Effects Of Forests On Landslides, SDU Faculty Of Forestry Journal, 15: 8493.
Forbes, K., Broadhead, J., 2011. Forests and Landslides: The role of trees and forests in the prevention of landslides and rehabilitation of landslide-affected areas in Asia. Rap Publication 19.

Johansson, T., Heiskanen, J., Siljander, M., Pellikka, P., 2019. Web Map Application to Support Spatial Planning, Decision-Making and Transition Toward Climate-Smart Landscapes in the Taita Hills, Kenya. Advanced Computing and Systems for Security, 173187.

Karnatak H. C., 2016. Geo Web Services Technology and Applications, SPIE APRS Symposium 2016, Apr, New Delhi.

Kumar, S.V., Bhagavanulu, D.V.S., 2008. Effects of deforestation on landslides in Nilgiris District: a case study. J. Indian Soc. Remote Sens. 36:105-108.

Lajis A., Nasir H. M. and Ismail N., 2016. Web GIS based information visualization for pest infection: a case study of rice plantation. Asian J Plant Sci 15(34):109-114.

Li, S., Saborowski, J., Nieschulze, J., Li, Z., Lu, Y., Chen, E., 2007. Web service based spatial forest information system using an open source software approach. Journal of Forestry Research, 18(2):8590.

Neumann A., 2012. Web Mapping and Web Cartography, Springer Handbook of Geographic Information, 273-287.

GDF, 2017. Forestry Statistics, General Directorate of Forestry, Turkish Statistical Institute Publications, Ankara.

Ramsey, P., 2006. The State of Open Source GIS, Refraction Research Inc., $42 \mathrm{p}$.

Rice, R.M., 1977. Forest management to minimize land slide risk, FAO Conservation Guide, Guidelines for Watershed Management.

Scharl, A., Tochtermann, K., 2009. The Geospatial Web: How Geobrowsers, Social Software and the Web 2.0 are Shaping the Network Society, Springer Science \& Business Media, ISBN: 1846288266.

Shen, J., Grossmann G., Yang Y., Stumptner M., Schrelf, M., Reiter T., 2007. Analysis of business process integration in Web service context, Future Generation Computer Systems, 23(3):283-294 p.

Sherman G. E., 2008. Desktop GIS: Mapping the Planet with Open Source Tools, p. 368, 2008-10-15, ISBN: 978-1-93435-606-7.

Steiniger, S., Hunter, A.J.S., 2012. Free and open source GIS software for building a spatial data infrastructure, in: Proc Geospatial free and open source software in the 21st century, Nantes, France, 247-261.

Tayyebi A., Meehan T. D., Dischler J., Radloff G., Ferris M. and Gratton C., 2016. SmartScape: a webbased decision support system for assessing the tradeoffs among multiple ecosystem services under cropchange scenarios. Comput Electron Agric, 121:108121. 
Torre, J., 2005. Report of existing GIS standards and software - Deliverable 3.6.1, Core GIS 6.1,icesSYNTHESYS NA-D 3.6 report, $11 \mathrm{p}$.

Turan F., 2006. Web Services Based Geographical Informatıon Systems, Başkent University, Master Thesis, $177 \mathrm{p}$.

Turner T. R., Duke S. D., Fransen B. R., Reiter M. L., Kroll A. J., Ward J. W., Bach J. L., Justice T.E., Bilby
R.E., 2010. Landslide densities associated with rainfall, stand age, and topography on forested landscapes, southwestern Washington, USA. Forest Ecology and Management 259:2233-2247.

Zhang, D., Chen, X., Yao, H., 2015. Development of a prototype web-based decision support system for watershed management. Water, 7(2):780-792. 